\title{
THE ADHESION OF ICE SPHERES IN ELEGTRIG FIELDS
}

\author{
By J. Latham and C. P. R. Saunders \\ (Department of Physics, University of Manchester Institute of Science and Technology, \\ Manchester, England)
}

\begin{abstract}
Aвstract. The force $F$ required to separate two ice spheres was measured as a function of environmental temperature $T$, relative humidity $H$ and the strength $E$ of the external electric field in which the spheres were situated. It was found that over the entire attainable range of $T$ and $H, F$ increased rapidly with increasing $E$. The increased adhesion was not accompanied by an increase in the rate of growth of the ice bridge between the two spheres and is explicable in terms of Davis's (1964) calculations of the purely electrostatic forces between two spheres situated in an electric field. The experiments indicate that the rate of growth of snowflakes in a cloud by means of ice crystal aggregation will be markedly enhanced if the cloud is highly electrified.
\end{abstract}

RÉsumé. L'adhésion de sphères de glace dans des champs électriques. La force $F$ nécessaire pour séparer deux sphères de glace a été mesurée en fonction de la température ambiante $T$, de l'humidité relative $H$ et de la force $E$ du champ électrique externe dans lequel était placé les deux sphères. Il a été mis en évidence que, pour toutes les valeurs possibles de $T$ et de $H, F$ augmentait rapidement avec $E$ croissant. L'adhésion croissante n'était pas accompagnée par une augmentation de la vitesse de croissance du pont de glace entre les deux sphères; elle est explicable dans les termes du calcul de Davis (1964) des forces purement électrostatiques entre deux sphères placées dans un champ électrique. Les expériences indiquent que la vitesse de croissance de flocons de neige dans un nuage par aggrégation de cristaux de glace serait sensiblement augmentée si le nuage était fortement électrifié.

Zusammenfassung. Die Adhäsion von Eiskugeln in elektrischen Feldern. Die zur Trennung zweier Eiskugeln erforderliche Kraft $F$ wurde in Abhängigkeit von der Umgebungstemperatur $\mathcal{T}$, der relativen Feuchte $H$ und der Stärke $E$ des äusseren elektrischen Feldes, in dem die Kugeln gelagert waren, gemessen. Es ergab sich, dass über den ganzen verfügbaren Bereich von $T$ und $H$ die Kraft $F$ mit zunehmendem $E$ rasch zunahm. Die stärkere Adhäsion war nicht mit einer Zunahme der Wachstumsgeschwindigkeit der Eisbrücke zwischen den beiden Kugeln verbunden; sie lässt sich mit Hilfe von Davis' (1964) Berechnungen der rein elektrostatischen Kräfte zwischen zwei Kugeln in einem elektrischen Feld erklären. Die Versuche zeigen, dass die Geschwindigkeit des Wachstums von Schneeflocken in einer Wolke durch Zusammenballung von Eiskristallen beträchtlich ansteigt, wenn die Wolke elektrisch stark geladen ist.

\section{INTRODUCTION}

Much research has been performed in recent years in order to determine the mechanisms by which ice crystals originate inside a cloud, grow and then aggregate to form snowflakes which subsequently fall out of the cloud to reach the ground as rain, sleet or snow. Hosler and others (1957) studied experimentally the aggregation of ice crystals colliding with an ice sphere as a function of relative humidity and temperature. They found that at ice saturation no aggregation occurred at temperatures below $-25^{\circ} \mathrm{C}$. but that the degree of aggregation increased markedly as the temperature was increased above this value to $0^{\circ} \mathrm{C}$. A similar relationship was obtained when the collisions occurred in a dry atmosphere, but in this case the critical temperature below which adhesion was not observed was $-4^{\circ} \mathrm{C}$. In some separate experiments Hosler and others measured the force required to separate two ice spheres which had been brought into contact for a known time as a function of temperature and relative humidity. The requisite force was found to vary with temperature and relative humidity in exactly the same manner as had the degree of aggregation in their earlier experiments; the limiting temperatures separating zero from finite forces of separation were close to those measured in the aggregation studies.

Hosler and others concluded that their results were explicable in terms of the "liquid-like layer" hypothesis propounded in elementary form by Faraday (1860) and developed by Weyl (I95I). From considerations of minimum surface free energy Weyl proposed a reorientation of molecules in and near the surface of an ice specimen and that the thickness of this "liquid-like layer" will decrease with decreasing temperature and relative humidity. Circumstantial support for Weyl's hypothesis is provided by the experiments of Jellinek 
(I96r) and the theoretical studies by Fletcher (1962) who demonstrated that the reorientation of water molecules in an ice surface near $0^{\circ} \mathrm{C}$. extends in an exponentially decreasing manner for ten molecular layers below the surface before achieving the bulk-ice lattice arrangement, and that the theoretical relationship between the thickness of the distorted layer and temperature is similar to that between sticking force and temperature, measured by Hosler and others. However, although the "liquid-film" hypothesis offers an explanation for several experimentally determined properties of ice, these phenomena can also be explained in terms of well-established physical effects. Experiments by Kingery (1960) and Kuroiwa (I96r) indicated that surface and volume diffusion of ice molecules were primarily responsible for the sintering of ice, but a comprehensive theoretical and experimental study by Hobbs and Mason (1964) demonstrated conclusively that the dominant mechanism operative during the sintering of ice spheres in air at atmospheric pressure is evaporation of material from the surface of the spheres and condensation onto the concave region of the ice bridge growing between the two spheres.

Despite this apparently satisfactory explanation of the sintering of ice in a field-free environment little research has been conducted into the effect of electric fields upon the adhesion of ice to ice. Latham and Saunders (1964) established that the aggregation of ice crystals impinging against an ice sphere at $-9^{\circ} \mathrm{C}$. increased markedly with increasing external field strength above about $800 \mathrm{~V} . \mathrm{cm}$. $^{-1}$. However, these preliminary experiments were largely non-quantitative and lacked sufficient precision to determine the mechanisms responsible for the enhanced aggregation and the modifications of the rates of growth of precipitation particles which may occur in highly electrified clouds. The present study constitutes an attempt to establish quantitatively the effect of electric fields on the force required to separate two spheres of ice under different environmental conditions.

\section{The Adhesion Experiments}

Figure I shows the apparatus designed to measure the force required to separate two ice spheres as a function of temperature, relative humidity, duration of contact, and strength of electric field in the environment of the spheres.

A helical quartz spring of sensitivity $25 \cdot 8 \mathrm{~cm} . \mathrm{g} .^{-1}$ was suspended by means of a nylon fibre from a horizontal shaft. By the use of a gearing system the shaft could be rotated slowly thus raising or lowering the spring. Fixed rigidly to the end of the shaft was a calibrated circular dial which allowed the position of the spring to be noted. An ice sphere was frozen on to the base of an ebonite rod which was suspended from a fine glass rod affixed to the base of the spring. A second ice sphere of identical radius was mounted on top of an ebonite rod held rigidly in a micromanipulator which could be adjusted to make the axes of the two insulating rods collinear. A system of guides permitted the ice spheres to be joined and separated along their line of centres without the introduction of twisting couples, as had been present in the experiments of Nakaya and Matsumoto (1954) and Hosler and others (1957). Two brass electrodes in the form of smoothed toroidal rings were situated $3 \mathrm{~cm}$. apart straddling the two ice spheres in contact. Application of a potential difference between the electrodes by means of a continuously variable high voltage supply enabled the creation between them of an electric field parallel to the line of centres of the spheres; fields ranging from o to $3,000 \mathrm{~V} . \mathrm{cm} .^{-1}$ could be used. The spring was encased in a protective perspex box and the whole apparatus, held rigidly by metallic supports, was placed inside a refrigerator whose temperature, measured by means of a thermocouple, could be varied from $0^{\circ} \mathrm{C}$. to $-15^{\circ} \mathrm{C}$. and maintained constant to within $\pm 0 \cdot 5^{\circ} \mathrm{C}$.; the refrigerator was placed on antivibration mountings. A mirror system and an illuminating lamp, not shown in the diagram, enabled the ice spheres to be viewed from outside the refrigerator by means of a telescope. The ice spheres were formed in situ within the refrigerator by freezing water drops of pre-selected volume and 


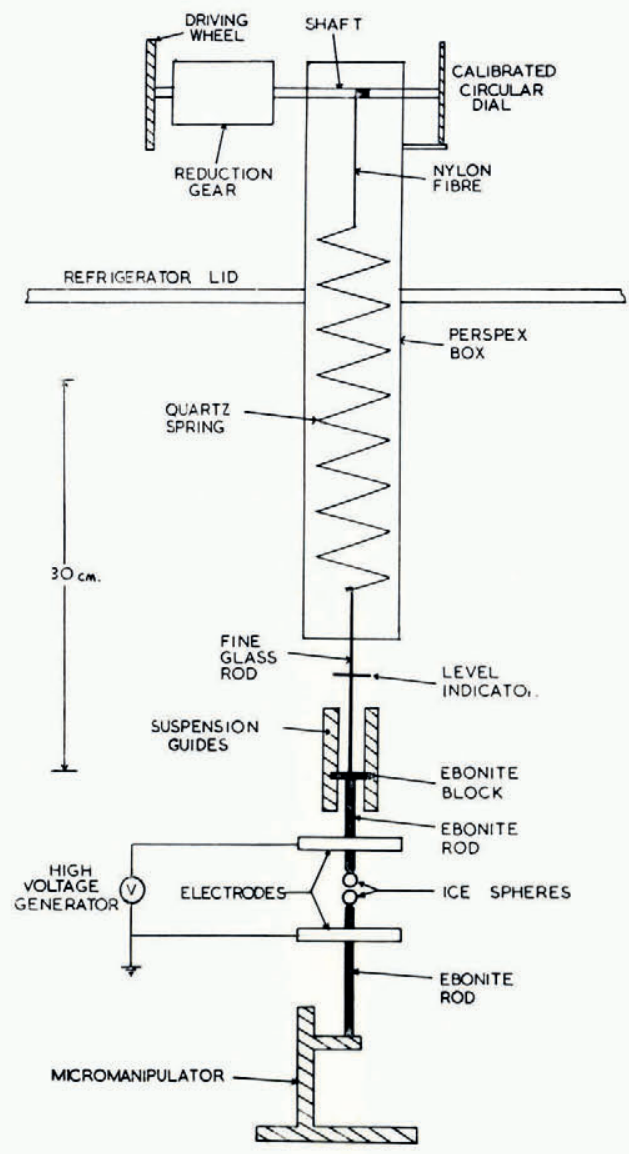

Fig. I. Apparatus for measuring the force required to separate ice spheres

discarding the ones whose surfaces were not smooth and spherical. Ice spheres of radii $R_{\mathrm{I}}$ (upper) and $R_{2}$ (lower) ranging from $0.1 \mathrm{~cm}$. to $0.3 \mathrm{~cm}$. were used and were allowed to attain temperature equilibrium before being brought into contact.

The experimental procedure was to position the upper ice sphere centrally between the electrodes and, using the micromanipulator, to raise the lower sphere until it made gentle contact with the upper one. The reading on the graduated dial was then noted. The spheres were allowed to remain in contact for a measured time in a field of pre-selected strength and were then separated by revolving the handle attached to the graduated dial. The difference between the dial readings at the points of contact and separation provided an accurate measurement of the force required to separate the ice spheres. The force of separation $F$ could be measured accurately to within \pm 0.2 dyn. Several readings of $F$ were made for the same values of temperature $T$ and field strength $E$ and the entire procedure was then repeated for different values of these parameters. Measurements of $F$ were also made for different values of environmental relative humidity $H$ which was measured using the hygrometer devised by Latham and Stow (1964). Three values of $H$ were used: $H=0$, which was achieved by ventilating the spheres with a gentle stream of dry nitrogen which had been precooled to attain the temperature of the refrigerator; $H=5 \mathrm{r} \%$, which was the normal value 
within the refrigerator; and $H=100 \%$, which was effected by surrounding the electrodes and ice spheres with an insulated box whose interior walls were coated with ice. In order to reduce the considerable scatter obtained in the measured values of $F$, which are a consequence of the statistical nature of the mechanism of separation, some experiments were performed with the lower ice sphere replaced by a plane ice surface. This substitution rendered impossible a knowledge of the absolute value of $E$ between the ice surfaces but it was justifiable to make quantitative comparisons of the values of $F$ obtained using this technique for particular values of $E, T$ and $H$ with values of $F$ measured for different values of these three parameters obtained under the same situation, which is designated by the expression $R_{2}=\infty$. The effect of the time of contact $t$ upon the measured values of $F$ was also investigated.

Figure 2 demonstrates that negligible force is required to separate ice spheres of equal radius $0.120 \mathrm{~cm}$. brought into contact in a dry environment in the absence of an electric field when the environmental temperature was below about $-4 \cdot 5^{\circ} \mathrm{C}$. However, at higher temperatures the values of $F$ are seen to increase rapidly. The curve of $F$ against $T$ is of similar shape to that obtained by Hosler and others (1957) for larger spheres when $H=0$ and $F=0$. The slight decrease of the threshold temperature measured in the present experiments is probably a consequence of the higher vapour-pressure gradient existing in the vicinity of the ice bridge when the radius of curvature is decreased.

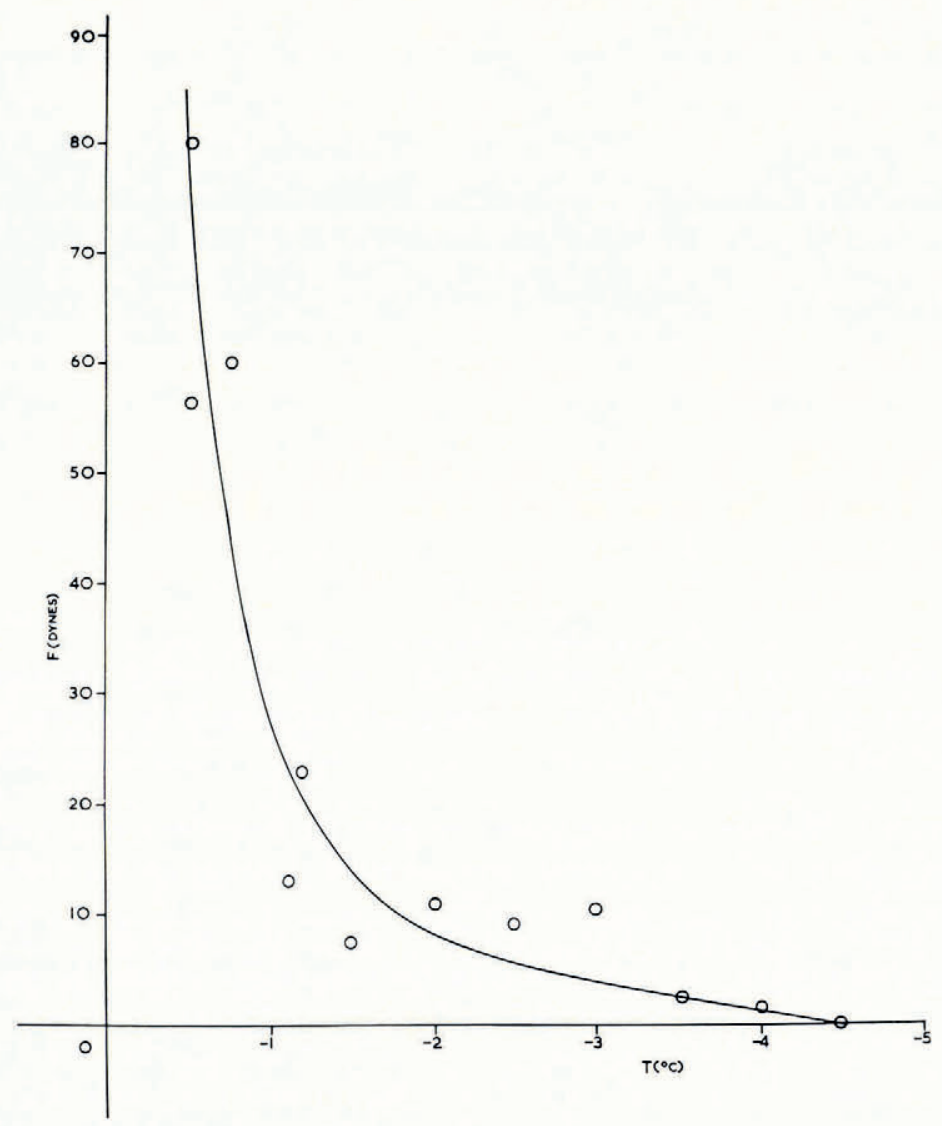

Fig. 2. The force $F$ required to separate ice spheres as a function of temperature. $T$. $R_{1}=R_{2}=0.120 \mathrm{~cm} . ; H=o ; E=o$ 
Figure 3 demonstrates that the difference $\Delta F$ between the force $F$ required to separate ice spheres of radii $R_{1}=R_{2}=0 \cdot 125 \mathrm{~cm}$. which had made contact for a period of $t=\mathrm{I} \min$. at a temperature $T=-\mathrm{I} 5^{\circ} \mathrm{C}$. in an environment of relative humidity $H=5 \mathrm{I} \%$ and the field-free force of separation, $F_{0}$, increases rapidly with an increase in the strength of the electric field $E$ in which they are situated. Considerable scatter is seen to exist in the individual values of $\Delta F$, owing to the difficulty of attaining reproducible contacts. Since the force required to separate similar ice spheres under these conditions of temperature and humidity in the absence of an electric field was found to be $8 \cdot 0$ dyn. the values of $\Delta F$ shown in Figure 3 indicate an increase above the field-free value of $4 \cdot 0$ dyn. and $18.5 \mathrm{dyn}$. for fields of $\mathrm{I}, 000 \mathrm{~V} . \mathrm{cm} .^{-1}$ and $2,000 \mathrm{~V} . \mathrm{cm} .^{-1}$ respectively. A similar marked increased in the measured values of $\Delta F$ with increasing $E$ is evident from Figures 4 and 5 which were obtained with contacts between an upper ice sphere of radius $R_{\mathrm{I}}=0.145 \mathrm{~cm}$. and a plane ice surface at relative humidities $100 \%$ and zero respectively and a temperature $T=-10^{\circ} \mathrm{C}$. Comparison of Figures 4 and 5 indicates that the increase in the force of adhesion is virtually independent of $H$. It was also discovered that the values of $F$ were independent of contact time over a range Io sec. to $5 \mathrm{~min}$. and were independent of the fraction of the contact time over which the field was applied, provided that the field was on at the time that the spheres were separated. However, if the field was switched off just before separation the measured values of $F$ were markedly reduced and if sufficient time was allowed to elapse for the polarization charges to

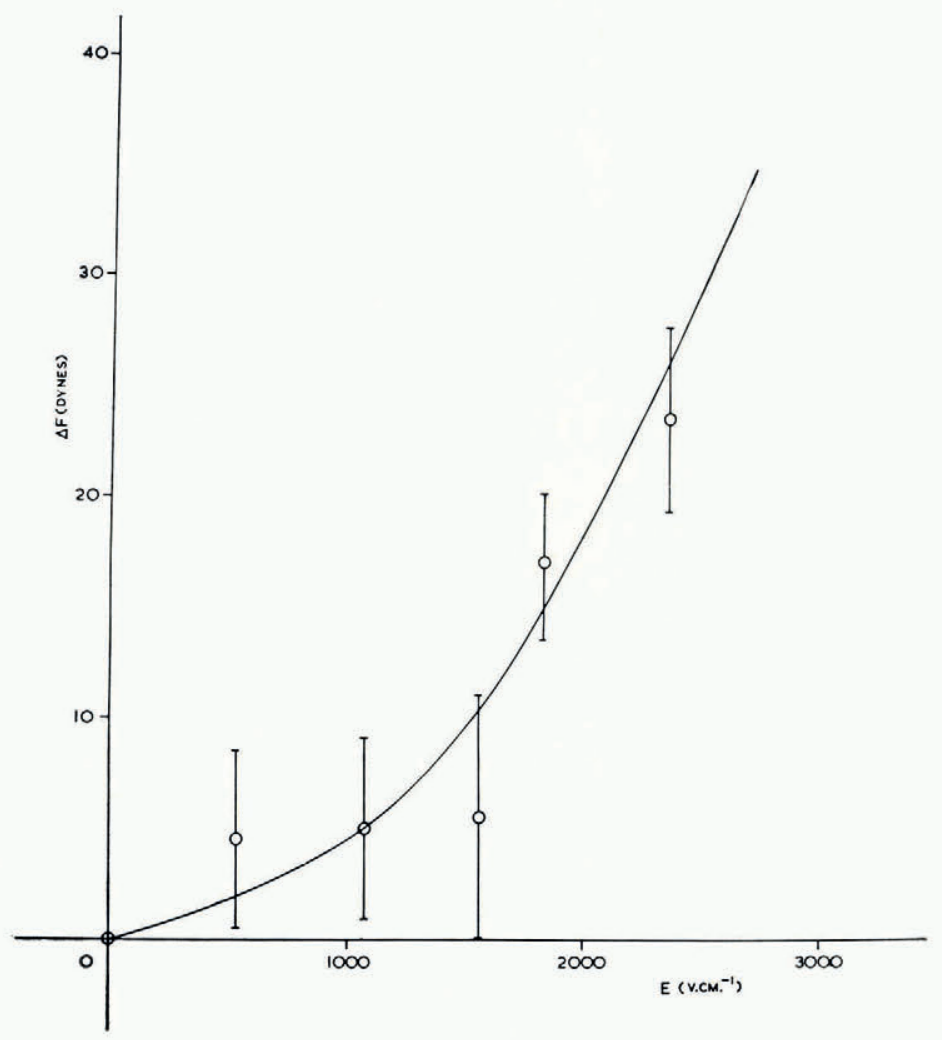

Fig. 3. The additional force $\Delta F$ required to separate ice spheres as a function of external field strength $E$. $R_{1}=R_{2}=0 \cdot 125 \mathrm{~cm}$.; $H=51 \% ; T=-15^{\circ} \mathrm{C}$. 


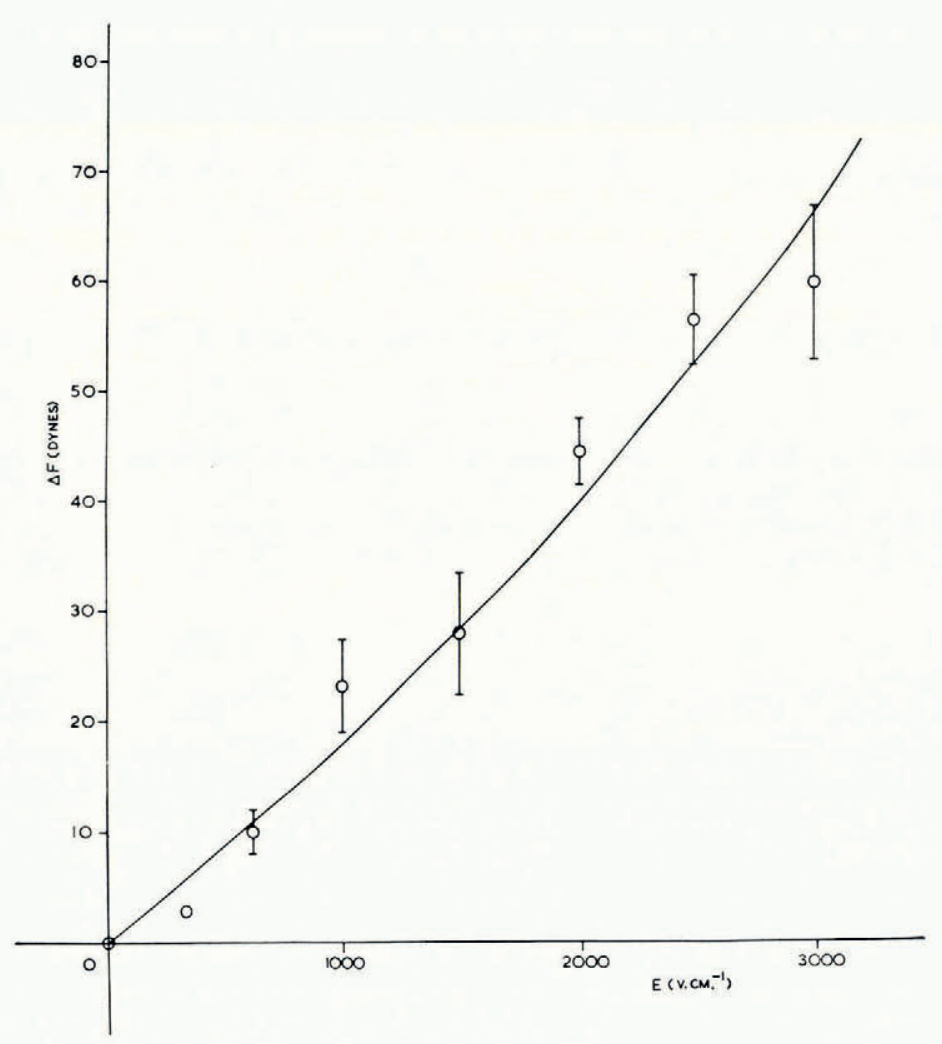

Fig. 4. The additional force $\Delta F$ required to separate ice spheres as a function of external field strength $E$. $R_{1}=0 \cdot 145 \mathrm{~cm} . ; R_{2}=\infty ; H=100 \% ; T=-10^{\circ} \mathrm{C}$.

leak away before separation was effected the measured values of $F$ were found to be identical with those obtained when the ice spheres were brought into contact for the same period in the absence of an electric field.

The apparatus illustrated in Figure 6 was situated within a refrigerator in order to determine whether the rate of growth of the ice bridge formed between two ice spheres in contact was affected by the presence of an electric field. Ice spheres of radii equal to those used in the main experiments were mounted on glass fibres and brought into gentle contact with their line of centres parallel to the axes of the fibres using the accurate adjustment devices shown in the figure. An electric field parallel to the line of centres of the spheres was produced by applying a potential difference obtained from a continuously variable power supply between the two toroidal brass electrodes. The ice spheres were formed by freezing water drops suspended from the glass rods oriented in the vertical. The whole apparatus was then rotated through $90^{\circ}$, using the hinge and pivot system, to attain the configuration illustrated in the diagram. The rate of growth of the ice bridge between the spheres was measured visually and photographically using a travelling microscope, read to $\pm 5 \mu$, which was mounted outside the refrigerator. It was found that the rate of growth of the ice bridge was independent of field strength over a period of contact of several hours for all values of relative humidity and temperature. The results were in good agreement with those of Hobbs and Mason for ice spheres made from both pure water and $\mathrm{NaCl}$ solutions of strength up to 


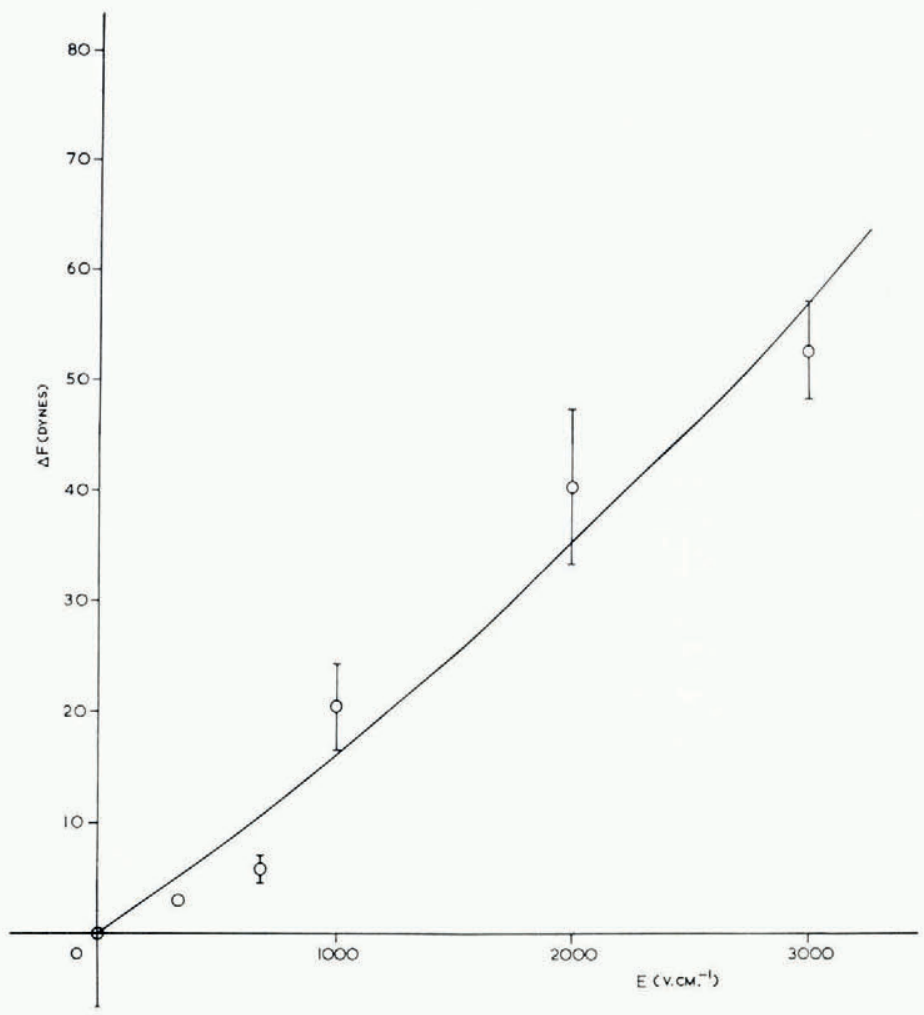

Fig. 5. The additional force $\Delta F$ required to separate ice spheres as a function of external field strength $E$. $R_{1}=0.14 .5 \mathrm{~cm} . ; R_{2}=\infty ; H=o ; T=-10^{\circ} \mathrm{C}$.

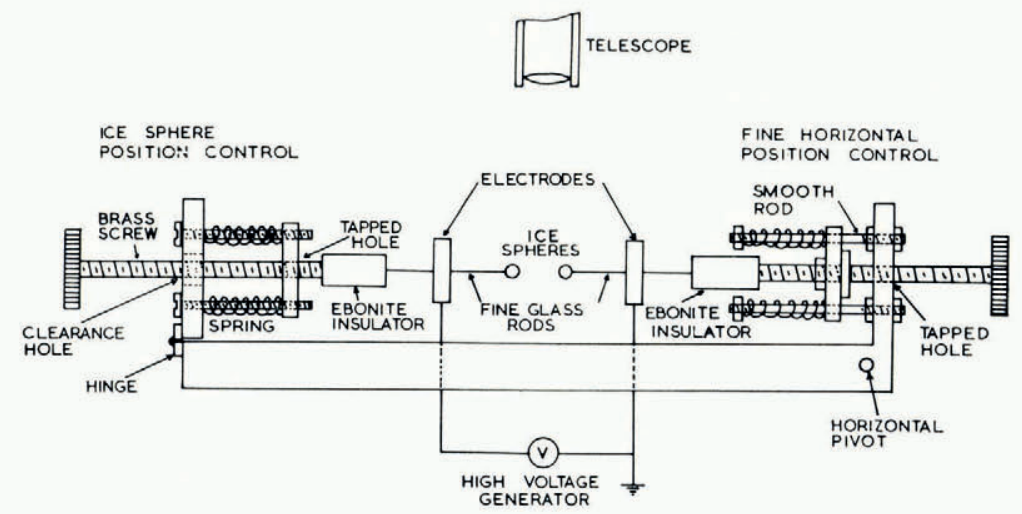

Fig. 6. Apparatus for measuring the rate of neck growth between ice spheres in an electric field 
fifty times that possessed by melted hailstones $\left(3 \cdot 6 \times 10^{-3} \mathrm{~g} \cdot 1^{-1}\right)$. The insensitivity of the rate of growth of the ice bridge to the strength of the prevailing electric field has been confirmed by Dye and Hobbs (personal communication). This finding is consistent with the observation, made in the previous experiment, that after the polarization charges had been allowed to leak away before separation, the force required to separate two ice spheres which had been held in contact in the presence of a field was identical with that required to separate them if the field had been zero throughout the period of contact and separation.

\section{Discussion}

It is unnecessary to invoke increased bridge growth or enhanced bonding in order to explain the observed increase of $F$ with increasing $E$. The measured increase of $F$ in the presence of an external field is explicable, qualitatively and quantitatively, in terms of the additional work required to separate spheres polarized in the field. Davis ( 1964 ) showed that the force of attraction $F$, between two rigid uncharged spheres of radii $R_{1}$ and $R_{2}$ (where $R_{\mathrm{I}} \geqslant R_{2}$ ) whose line of centres is parallel to the external uniform electric field of strength $E$ in which they are situated is given by the equation

$$
F_{1}=\epsilon R_{2}^{2} E^{2} A
$$

where $\epsilon$ is the specific inductive capacity of the medium in which the spheres are situated. The coefficient $A$ is a function of $R_{\mathrm{I}} / R_{2}$ but is much more sensitive to the separation $S$ of

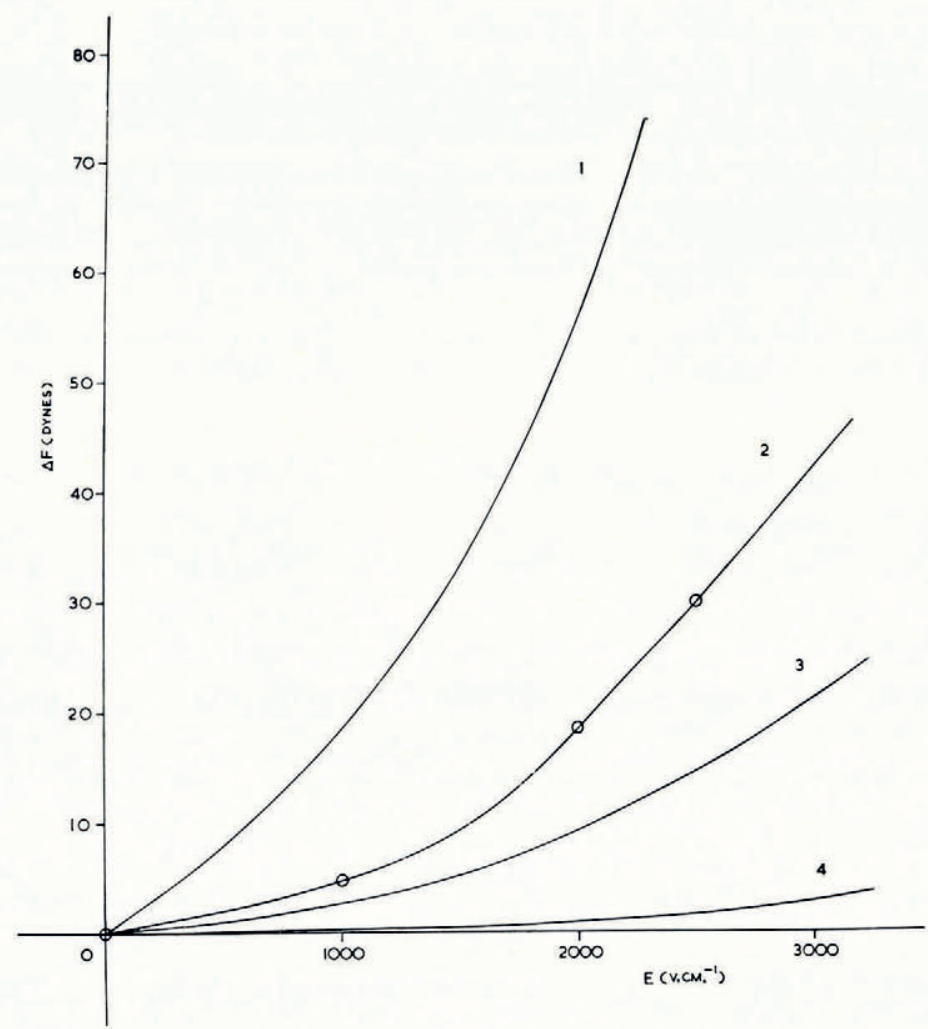

Fig. 7. The additional force $\Delta F$ required to separate ice spheres as a function of external field strength $E$. - - experimental points obtained from Figure 3. $1,2,3,4$-theoretical curves for $S$ equal to $I \mu, 4 \mu, 10 \mu$ and $100 \mu$ respectively derived from measured $R_{1}$ and $R_{2}$ 
the spheres. For example if $R_{1}=R_{2}$ the values of $A$ corresponding to separations $S / R_{2}$ given by $\mathrm{I} 0 \cdot 0,0 \cdot \mathrm{I}$, and $0 \cdot 00 \mathrm{I}$ are $3 \times \mathrm{IO}^{-4}, \mathrm{I} \cdot 40$ and $59 \cdot 49$ respectively. The rapid increase of $A$ with decreasing separation is a consequence of the enhanced mutual interaction of the polarization charges at closer separations. In order to compute theoretically the additional force required to separate two ice spheres if they are situated in an electric field over that required for separation in the absence of a field it is assumed that the separation of the curved surfaces of the ice spheres at the moment at which the bond is broken is of the order of the dimensions of the surface irregularities of the spheres, and is therefore between $\mathrm{I} \mu$ and г $\mu$. For a chosen value of initial separation $S$ and sphere radii $R_{1}$ and $R_{2}, A$ can be computed from Davis's tables and inserted into equation (I) together with the values of $R_{2}, E$ and $\epsilon$ (= I, air) to calculate theoretical values of the additional force $F_{\mathrm{I}}$ which can be compared with the experimentally determined values, $\Delta F$. In order to compute $F_{\mathrm{I}}$ when the lower ice surface was plane, the lower ice specimen was approximated to an ice sphere of equivalent radius whose surface density of charge at the closest point of separation to the upper sphere was equal to that possessed by the plane specimen.

Figure 7 shows that the experimental curve of $\Delta F$ against $E$ obtained with $H=5 \mathrm{I} \%$ and plotted in Figure 3 is consistent with the theoretical curve derived from equation (I) if the value of $S$ is taken to be $4 \mu$. The experimental curve is seen to lie between theoretical curves derived for $S=\mathrm{I} \mu$ and $S=\mathrm{I} 0 \mu$. Figure 8 shows that the experimental curves

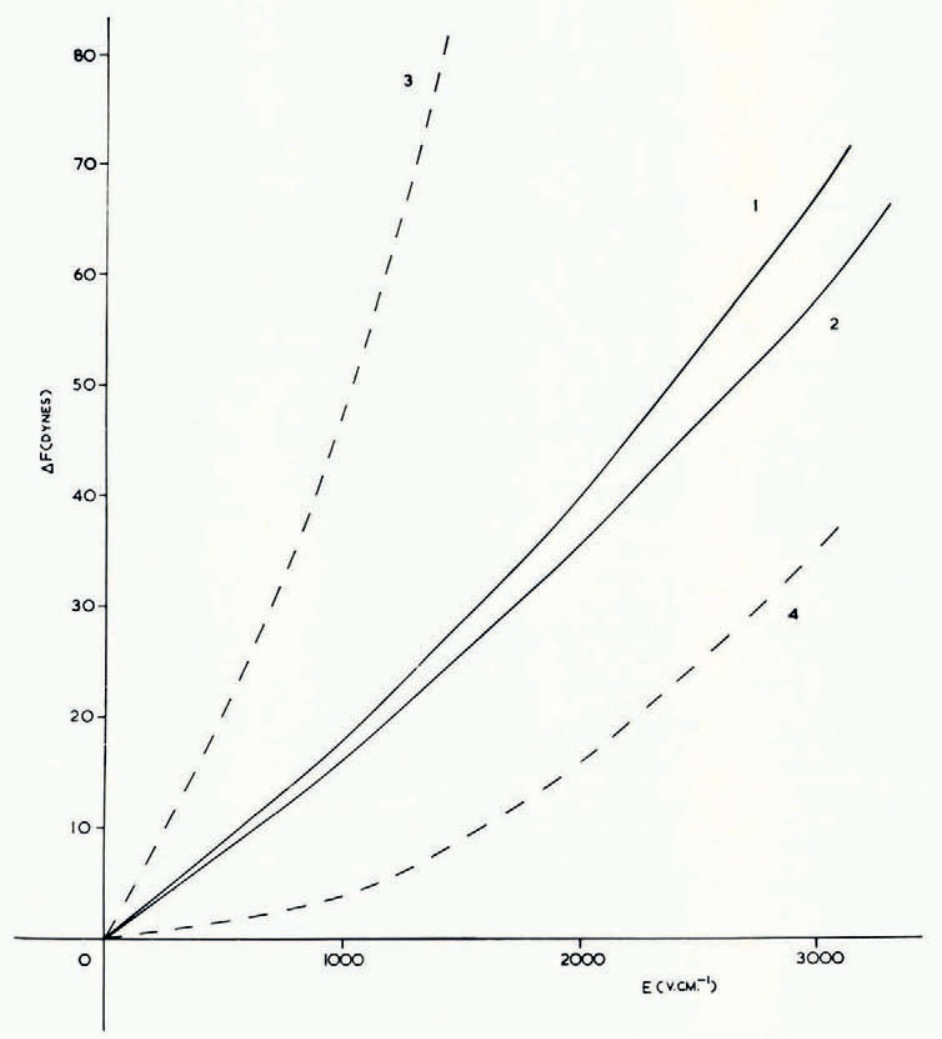

Fig. 8. The additional force $\Delta F$ required to separate ice spheres as a function of external field strength $E$. $I, 2-$ experimental curves obtained from Figures 4 and 5 respectively. 3,4 -theoretical curves derived from measured $R_{1}$ and $R_{2}$, for $S$ equal to $\mathrm{I} \mu$ and $\mathrm{IO} \mu$ respectively 
obtained with $H=100 \%$ and $H=0$, previously plotted in Figures 4 and 5 respectively, also lie between the theoretical curves derived for $S=\mathrm{I} \mu$ and $S=\mathrm{I} 0 \mu$. The actual value of $S$ will, of course, vary slightly from experiment to experiment, since the ice sphere geometry cannot be rigidly standardized, but $S$ should always lie between these two extremes, which have been shown to straddle the experimental points.

It appears, therefore, that the increased force required to separate ice spheres in the presence of an electric field is quantitatively explicable in terms of the calculations of Davis, and is therefore attributable to the additional work required to overcome the electrostatic attraction between the polarization charges on the spheres. This explanation is also consistent with the observations, which are inexplicable in terms of increased solid bonding, neck growth, or the "liquid-like layer" hypothesis, that the experimental values of $\Delta F$ are insensitive to the relative humidity and do not depend upon the time at which the field is applied during the experiment, provided that it is present at the moment of separation.

These experiments suggest that the rate of growth of snowflakes by means of ice crystal aggregation is unlikely to be significantly affected by the electric fields which are present throughout the great volume of most supercooled clouds. However, over localized regions of mature thunderclouds where the field strengths approach breakdown values the rate of growth of snowflakes should be markedly enhanced. Experiments are presently being conducted inside a large cold room in order to make quantitative measurements of this effect.

\section{ACKNOWLEDgements}

One of us (C.P.R.S.) wishes to acknowledge the receipt of an S.R.C. studentship during the course of this work.

MS. received 23 June 1966

\section{REFERENCES}

Davis, M. H. 1964. Two charged spherical conductors in a uniform electric field: forces and field strength. Quarterly Journal of Mechanics and Applied Mathematics, Vol. 1 7, Pt. 4, p. 499-51 1.

Faraday, M. 1860. Note on regelation. Proceedings of the Royal Society, Vol. 10, p. 440-50.

Fletcher, N. H. 1962. Surface structure of water and ice. Philosophical Magazine, Eighth Ser., Vol. 7, No. 74, p. $255-69$.

Hobbs, P. V., and Mason, B. J. 1964. The sintering and adhesion of ice. Philosophical Magazine, Eighth Ser., Vol. 9, No. 98, p. 181-97.

Hosler, C. L., and others. I 957 . On the aggregation of ice crystals to form snow, by C. L. Hosler, D. C. Jensen and L. Goldshlak. Fournal of Meteorology, Vol. 14, No. 5, p. 41 $5^{-20}$.

Jellinek, H. H. G. ig6r. Liquidlike layers on ice. Fournal of Applied Physics, Vol. 32, No. 9, p. I793. [Letter.]

Kingery, W. D. r96o. Regelation, surface diffusion, and ice sintering. Journal of Applied Physics, Vol. $3 \mathrm{I}$, No. 5 , p. $833-38$.

Kuroiwa, D. 196r. A study of ice sintering. Tellus, Vol. 13, Nr. 2, p. 252-59.

Latham, J., and Saunders, C. P. R. r964. Aggregation of ice crystals in strong electric fields. Nature, Vol. 204, No. 4965 , p. I $293-94$. [Letter.]

Latham, J., and Stow, C. D. 1964. A hygrometer for use at low temperatures. Fournal of Scientific Instruments, Vol. 41, No. 5, p. 324-26.

Nakaya, U., and Matsumoto, A. 1954. Simple experiment showing the existence of "liquid water" film on the ice surface. Fournal of Colloid Science, Vol. 9, No. I, p. 41-49.

Weyl, W. A. 195I. Surface structure of water and some of its physical and chemical manifestations. Fournal of Colloid Science, Vol. 6, No. 5, p. 389-405. 